\title{
Introduçào aos estudos sobre sangue e hemoglobinas de peixes realizados pela Expedição Alpha Helix
}

\author{
Austen Riggs (')
}

O navio R/V "Alpha Helix" é um laboratório de pesquisas planejado principalmente para estudos fisiológicos e financiado pela Fundação Nacional de Ciências dos Estados Unidos (U.S.A.). A série de publicações aqui apresentada é o resultado dos esforços realizados em novembro e dezembro de 1976, por um grupo internacional de 22 cientistas, provenientes de 6 paises, para melhor compreender as propriedades e adaptações dos sangues e hemoglobinas dos peixes do Amazonas. Os peixes desta região foram, em parte, escolhidos para estes estudos por causa da extraordinária variedade presente: calcula-se que existam mais de 2000 espécies na bacia amazônica. Desejamos explorar as adaptações moleculares e fisiológicas das hemoglobinas às águas ácidas e, muitas vezes, hipóxicas; desejamos, também, analisar as mudanças nas propriedades das hemoglobinas associadas com as transições da respiração na água para a respiração de ar. Estávamos curiosos para determinar como o sangue e a hemoglobina poderiam adaptar-se, a fim de atender às necessidades de certos peixes que sobrevivem em águas muito hipóxicas e que, no entanto. não são capazes de respirar ar.

Parecia-nos possível que o sistema do citocromo oxidase, dos peixes, poderia, também, ter adaptações especiais a fim de satisfazer às necessidades de hipóxia dos peixes, de modo que foi feito um estudo dessa enzima, tanto em peixes que respiram o ar, diretamente, ou que respiram na água. Além disso, foram feitos estudos das hemocianinas de camarōes e caranguejos locais, das hemoglobinas do peixeboi e de um anfíbio sem membros, completamente aquático, o caecilio Typhlonectes.

A fisiologia respiratória dos peixes tropicais sul americanos começou com o trabalho clássico de G.S. Carter, L.C. Beadle e E.N.
Willmer em 1931-34. Estes pesquisadores, trabalhando em condições difíceis, estabeleceram os fundamentos para a maioria dos estudos posteriores. $\mathrm{Na}$ primeira expedição "Alpha Helix" ao Amazonas, em 1967, Kjell Johansen, Claude Lenfant, Knut Schmidt Nielsen, Jorge Petersen e seus colegas fizeram algumas observações importantes em vários peixes respiradores de ar, tendo ficado clara a sua validade para futuros estudos. Nessa atual expedição foi imediatamente subseqüente a uma outra organizada pelos Drs. David Randall e Peter Hochachka. Os resultados da sua expedição serão publicados no Canadian Journal of Zoology. A parte de seu trabalho relacionada à fisiologia respiratória foi concentrada principalmente nos fenômenos acima do nível molecular e, assim, os dois grupos de pesquisas destas duas expedições são complementares. Ambos os grupos estudaram muitos dos mesmos peixes. Dadas as incertezas na identificação de alguns peixes, tivemos o cuidado de conservar espécimes representativos das espécies críticas que se encontram depositadas no Museu de Zoologia da Universidade de São Paulc. Os resultados das duas expedições incluem os mais extensos exames da fisiologia respiratória e da bioquímica das hemoglobinas até agora realizados.

Aproximadamente $80 \%$ do trabalho da nossa expedição foram executados a bordo do navio; uma parte de cada amostra, no entanto, foi levada pelos participantes, aos respectivos laboratórios, para experimentos complementares. Tanto a variedade como a profundidade do trabalho feita no navio indica a versatilidade do "Alpha Helix". Praticamente, qualquer experimento bioquímico ou fisiológico pode se adequadamente projetado - ser realizado a bordo. Esta situação ideal é, até certo ponto, o resultado dos esforços do Dr. Per Scholander.

(1) - Department of Zoology, University of Texas, Austin, Texas 78712 . 

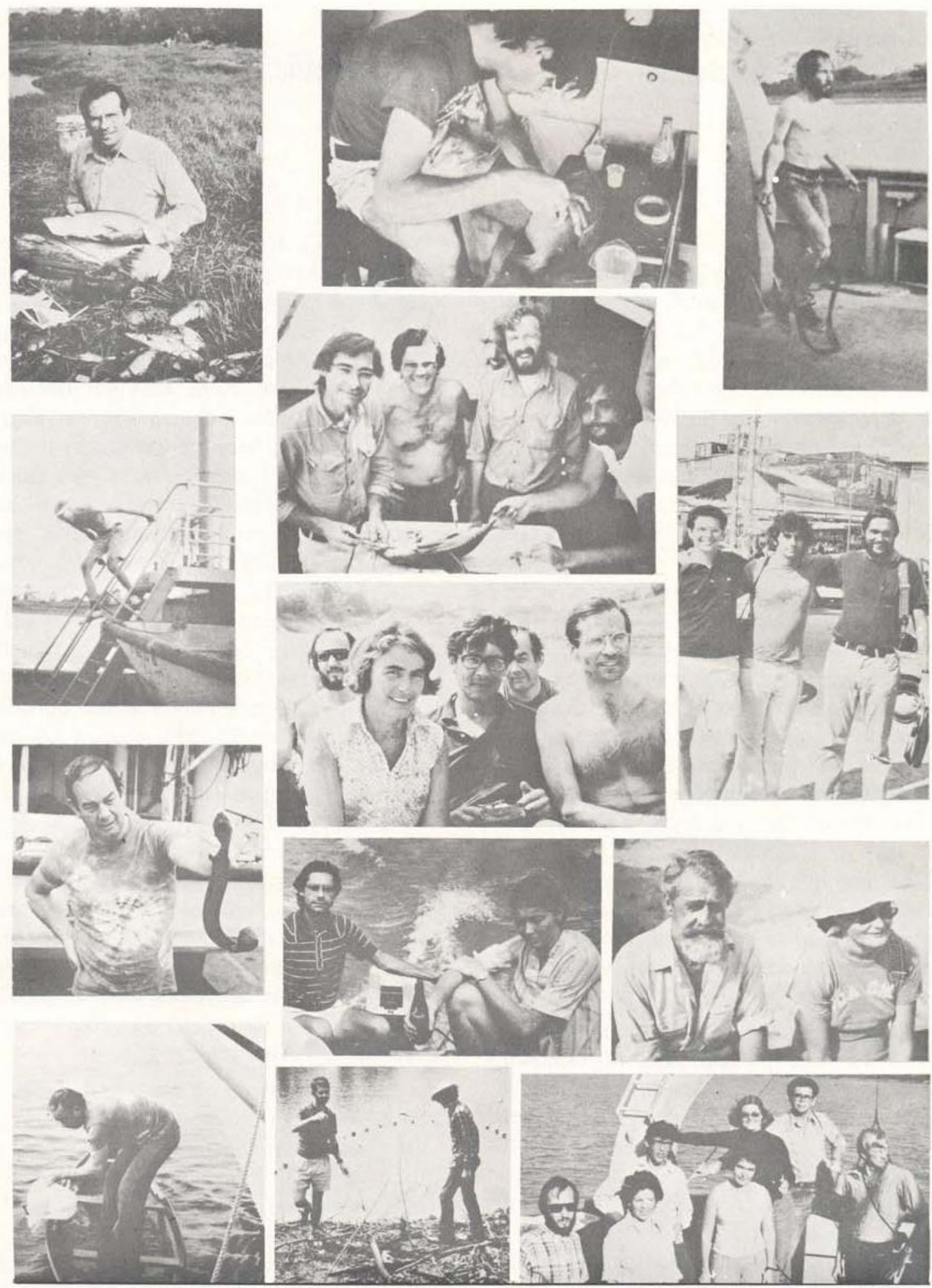

Fig. 1 - Primeira coluna de cima para baixo: (a) H.F. Bunn; (b) A. Riggs; (c) C. Phelps; (d) C. Phelps; segunda coluna de cima para baixo: (a) J. Bonaventura; (b) esquerda para direita: J. Bonaventura, M. Brunori, M. Wilson, R. Garlcik; (c) esquerda para direita: R. Noble, U. Fyhn, H. Fyhn, C. Phelps, H.F. Bunn; (d) esquerda para direita: J. Bonaventura, M. Farmer; (e) esquerda para direita: R. Weber, W. Fink; terceira coluna de cima para baixo: (a) R. Noble; (b) esquerda para direita: J. Martin, D. Powers, R. Garlick; (c) esquerda para direita: Capt. Geoffrey Clarke, J. Davis; (d) na frente, da esquerda para direita: R. Noble, I. Galdames-Portus, U. Fyhn, T. Fisher; atrás, da esquerda para direita: H. Fyhn, J. Davis, J. Martin. 

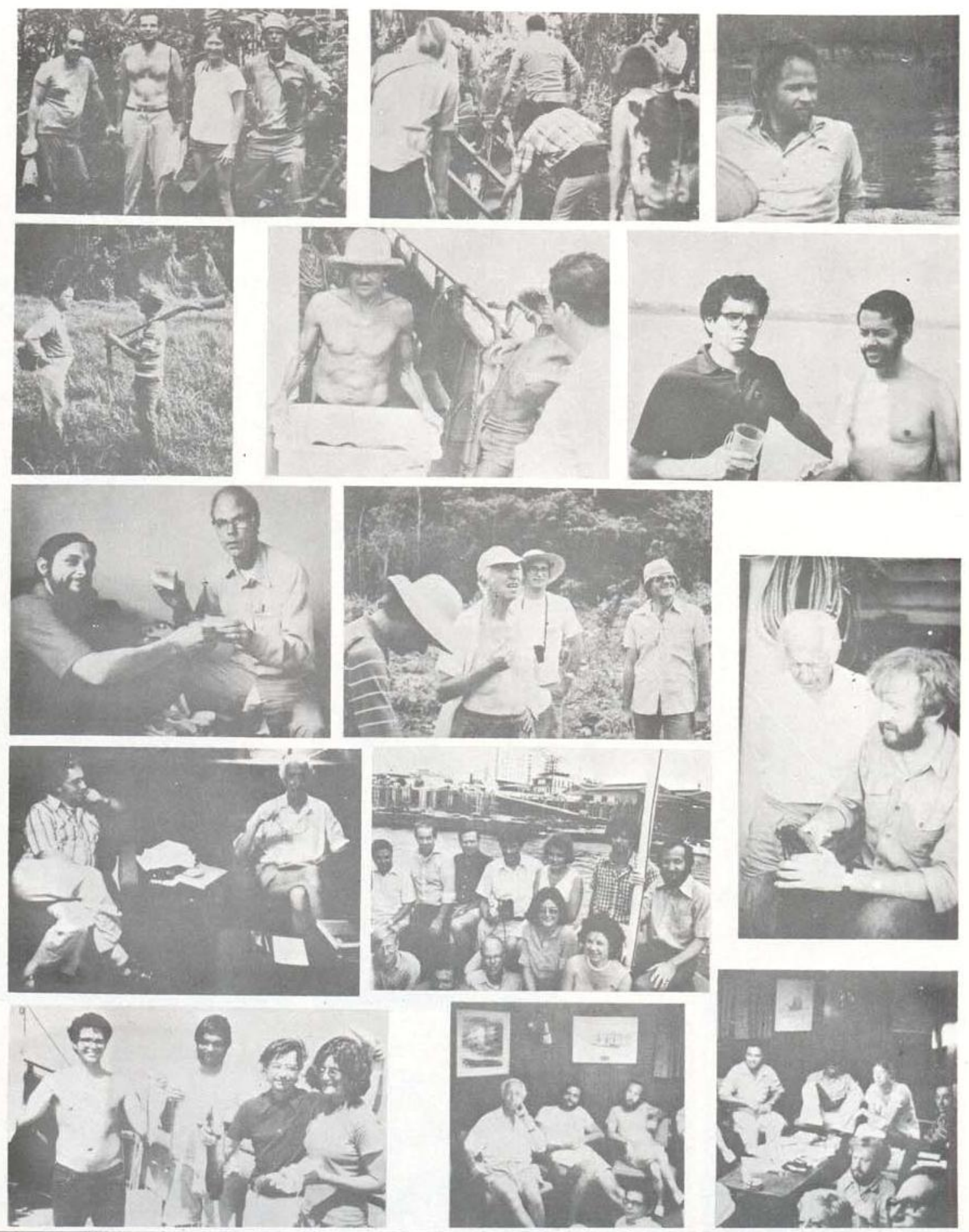

Fig. 2 - Primeira coluna de cima para baixo: (a) es querda para direita: C. Phelps, H.F. Bunn, M. Farmer, A. Riggs; (b) M. Perez e pescador armado; (c) esquerda para direita: R. Garlick e A. Riggs; (d) esquerda para direita: A. Focesi e J. Wyman; (e) esquerda para direita: J. Martin, R. Garlick, J. Bonaventura, J. Davis; segunda coluna de cima para baixo: (a) Transporte da canoa; (b) Juan (pescador); (c) esquerda para direita: J. Bonaventura, J. Wyman, M. Reichlin, M. Brunori; (d) atrás: M. Perez, C. Phelps, H.F. Bunn, H. Fyhn, U. Fyhn, D. Powers, R. Noble; frente: T. Fisher, R. Garlick, A. Riggs, J. Davis, I. Galdames Portus; (e) esquerda para direita: J. Wyman, R. Garlick, R. Noble; frente: J. Martin; Terceira coluna de cima para baixo: (a) S. Wood; (b) esquerda para direita: J. Martin, R. Weber; (c) esquerda para direita: J. Wyman. M. Wilson; (d) no sentido dos ponteiros do relógio a partir do esquerda superior: M. Perez, W. Fink, M. Farmer, J. Bonaventura, M. Reichlin, M. Wilson e A. Focesi. 

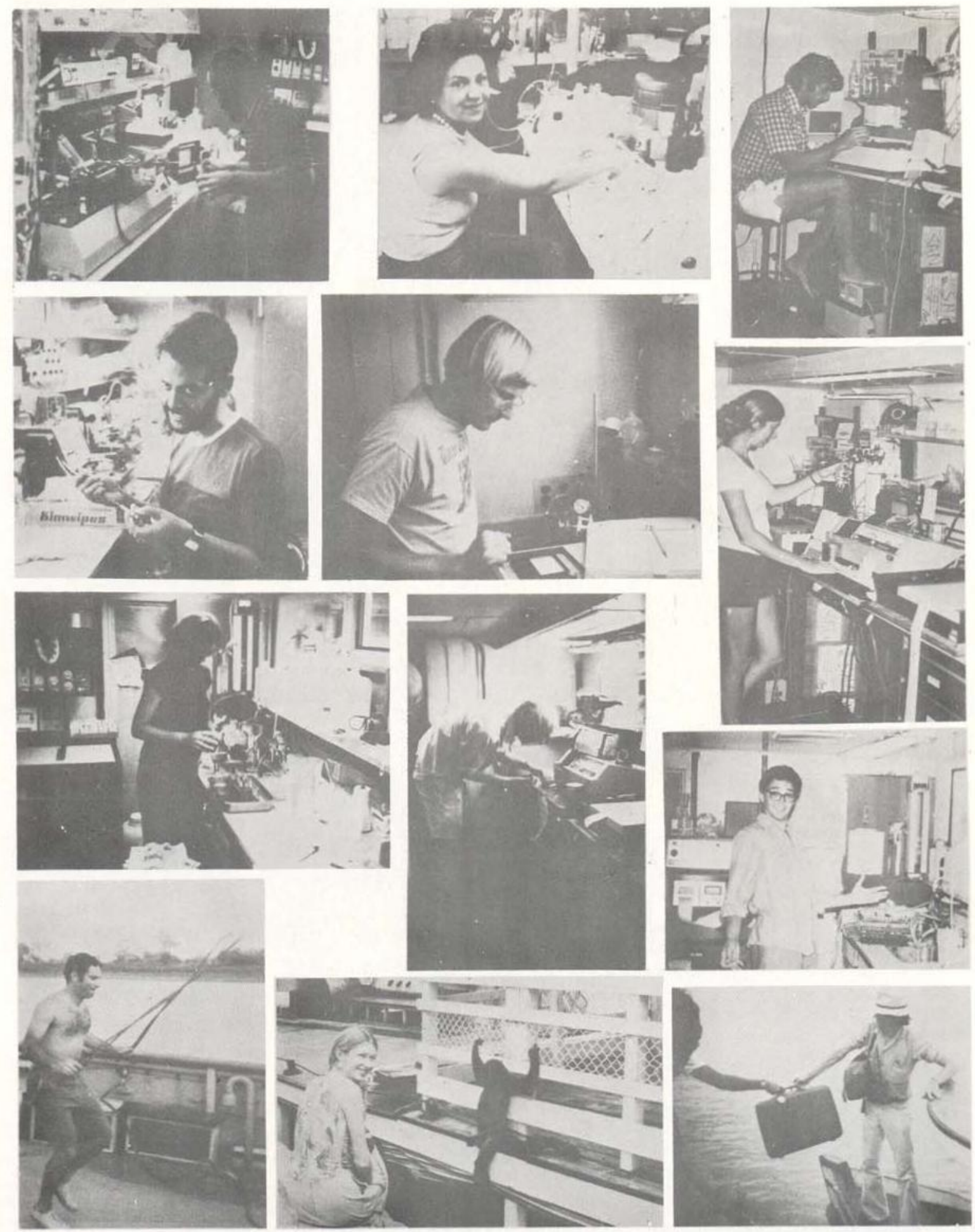

Fig. 3 - Primeira colura de cima para baixo: (a) R. Noble; (b) R. Weber; c) J. Davis; (d) M. Reichlin; segunda coluna de cima para baixo: (a) I. Galdames-Portus; (b) T. Fisher; (c) A. Riggs: (d) M. Farmer; terceira coluna de cima para baixo: (a) D. Powers; (b) M. Farmer; (c) J. Martin; (d) W. Fink. 
Foi ele quem persuadiu a "National Science Foundation" que o "Alpha Helix" seria um investimento científico de grande importância.

As publicações deste volume são alguns dos frutos desse investimento. Muitos dos experimentos não puderam ser feitos em 1931, por ocasião da expedição Carter-Beadle, porque, em muitos casos, não existiam instrumentos de alta precisão, como espectrofotómetros registradores e outros, hoje disponiveis. Porém, o mais importante é o roteiro de trabalho desenvolvido por Jeffries Wyman para lidar com fenômenos de função de Ligantes e processos cooperativos em macromoléculas. Ele tem transmitido suas reflexōes para a com. preensão do presente trabalho.
Esta Expedição agradece ao governo brasileiro a permissão dada para o $\mathrm{R} / \mathrm{V}$ "Alpha $\mathrm{He}$ lix" entrar até o alto Solimões. Agradecemos, em particular, ao Dr. Warwick Estevam Kerr, Diretor do INPA (Instituto Nacional de Pesquisas da Amazônia) e ao Dr. Paulo E. Vanzolini, Diretor do Museu de Zoologia da Universidade de São Paulo, pelo seu auxílio e cooperação. Somos gratos aos Drs. Heraldo Britski e Wolfgang J. Junk pelo seu apoio e auxílio. Prestounos ajuda, em várias oportunidades, o Comandante Manoel Perez, da Marinha Brasileira. Finalmente, a expedição não teria sido bem sucedida sem a agradável e alegre cooperação e apoio do Capitão Geoffrey Clarke e todos os membros de sua tripulação. 